\title{
The Employability of Pregnant and Breastfeeding Servicewomen
}

\author{
Maj AMJ Croft \\ MA, MSc, MBBS, RAMC \\ Senior Registrar in Public Health Medicine
}

Ministry of Defence, Army Medical Directorate, SO2 AMD5a, Keogh Barracks, Ash Vale, Aldershot, Hants GU12 5RR

SUMMARY: The Army Medical Services are responsible for promoting health in the military workplace. A survey of the potential health risks in the workplace to British Army servicewomen who are pregnant, or who breastfeed, was carried out. It was found that there was a total of $\mathbf{3 0}$ major workplace hazards to pregnant or breastfeeding servicewomen, and that medical guidance in this area was lacking. A Medline literature search on these hazards, was compiled, and an overview of the nature and extent of the military problem, together with a brief policy recommendation applying to each hazard. Guidelines based on these recommendations were distributed to primary care and obstetric unit medical officers in all three Armed Services. It is intended that the guidelines will assist Service doctors in giving informed advice on the avoidance of military occupational risks to pregnancy and to lactation.

\section{Introduction}

Since the disbandment of the Women's Royal Army Corps, women in the Regular Army can now serve in most Arms and Services. At present, only the Royal Armoured Corps and the Infantry remain closed to women.

From an occupational health perspective, one consequence of this development is that women of childbearing age are now being exposed by the Army to a much wider range of potential reproductive hazards than was the case formerly. Should they become pregnant, there is a risk of injury to the fetus from harmful agents in the workplace, and from adverse working conditions.

Medical officers who work in primary care obstetrics have a professional responsibility to be aware of these potential hazards, and to advise their Service patients accordingly. Where necessary, the attending medical officer must place a formal restriction on the employability of a pregnant servicewoman, in order to safeguard both her health and that of her unborn child.

During 1994 there were widespread allegations in the national press that the Ministry of Defence (MOD) had been negligent in its administrative management of pregnant servicewomen. In the clinical branch of the Army Medical Directorate (AMD5) it was realised at around this time that there was an almost complete lack of information available to Service medical officers on what military duties a pregnant servicewoman could and could not carry out with safety. There was a clear potential for civil litigation, and steps were therefore taken to remedy this deficiency in medical policy.

\section{Methods}

An initial study of the standard reference works on toxicology identified a number of obvious toxic hazards to pregnancy (eg noise, vibration, extremes of temperature) that would apply to most military workplaces. To ensure that the less common hazards were

not overlooked, AMD5 wrote to the Directors of all Arms and Services within the British Army, asking them to report on what they considered to be the main workplace hazards to the health of their pregnant and breastfeeding personnel. Consultation also took place with military occupational health specialists and with medicolegab advisers.

From the information received, a list was drawn up of 30 major reproductive hazards that exist in the militaro environment. A literature search from 1971 to the present was conducted on Medline with CD-ROM. Thos 8 published papers were retrieved which sought to postulate or to disprove a causal relationship between the identifies occupational hazards and an adverse outcome of pregnancy or of lactation.

In order to arrive at a concise recommendation for medical officers, an "on average" summary was made of the likely risk posed by each identified hazard to pregnancy or to breastfeeding. For certain reproductive hazards (eg lead, benzene, ionising radiation) it was found that the number of published research papers run into thousands. In these cases, heavy reliance was placed on existing review articles.

The collected guidelines were submitted to professional scrutiny and to modification where necessary, prior to being disseminated widely.

\section{Results}

The research findings are summarised in the form of Tables $1-5$. Referencing in the tables has been limited to major articles, or to key review papers. Towards the end of 1994, the tables were issued in booklet form to all primary care and obstetric unit medical officers in the British Army. In May 1995 they were distributed also to doctors in the Royal Navy and the Royal Air Force.

On account of their wider policy implications, the guidelines were circulated at an early stage by AMD5 to the manning and recruiting branches of the Army's 
Table 1

Workplace Hazards to Pregnancy Servicewomen - Physical Agents

\begin{tabular}{lll}
\hline Agent & \multicolumn{1}{c}{ Human Reproductive Hazard } \\
\hline 1.1 & IONISING & With high maternal exposures only: \\
RADIATION & congenital malformations, especially \\
& of central nervous system \\
& (including microcephaly and mental \\
& retardation). \\
& With lower maternal exposures: \\
& increased incidence of childhood \\
& cancers, particularly leukaemias.
\end{tabular}

\section{Scientific Evidence}

Numerous studies $(14,15)$

Numerous studies (14.15)

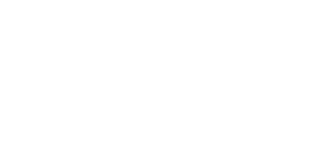

Recommendation for Medical Officer (MO)

Pregnant radiologists and radiographers are at a theoretical risk.

However, the nationally-recommended exposure levels for pregnant women are generally one-tenth of the upper limits recommended for non-pregnant workers. This should constitute sufficient protection for the foetus (14).

There is not therefore any requirement for an MO to impose additional restrictions.

\subsection{NON-IONISING Congenital malformations, perinatal} RADIATION deaths

SHORT-WAVE

EQUIPMENT

There exists one important study (16) of physiotherapists who had used short-wave therapeutic equipment whilst pregnant, with adverse effects on their pregnancies.
There are no known studies on the reproductive hazards of high-frequency radio sets (which operate on short wavelengths) but a sensible precaution would be to avoid them in pregnancy.

\begin{tabular}{lll}
\hline 1.3 & $\begin{array}{l}\text { NON-IONISING } \\
\text { RADIATION - }\end{array}$ & ??Spontaneous abortion. \\
& ??Congenital malformations
\end{tabular}

1.4. TRACKED VEHICLE NOISE

?Spontaneous abortion.
?Fetal growth retardation.
??Impaired hearing in offspring.

??Impaired hearing in offspring.

\begin{tabular}{ll}
\hline GUNFIRE \\
NOISE
\end{tabular}

$\begin{array}{lll}1.6 & \text { VIBRATION - } & \text { ?Preterm labour. } \\ \text { WHOLE-BODY } & \text { ?Low birth weight. }\end{array}$

\begin{tabular}{lll}
\hline 1.7 & VIBRATION - & ??Preterm labour \\
& HAND- & \\
& TRANSMITTED & ??Low birth weight.
\end{tabular}

\section{In fact the electromagnetic radiation emitted from VDUs is rarely if ever above natural background levels, except at the extremely low frequency end of the range (14).}

The epidemiological evidence to date does not support the suggestion that there is a causal relationship between adverse pregnancy outcome and VDU use (17-21).

Some studies have shown that prolonged exposure to industrial noise jeopardises the outcome of pregnancy, particularly when combined with shift work $(22,23)$. However, the majority of studies have not demonstrated such effects (14).

The preliminary data relating to the effect of industrial noise exposure of the mother on hearing levels in the offspring are difficult to interpret (24).

There are no known studies demonstrating a causal relationship between impulse noise and damage to the fetal auditory apparatus.

It would be difficult, however, to defend a legal action against MOD alleging childhood deafness as a consequence of exposure to gunfire noise in utero.

Some studies (25) have shown wholebody vibration to be a hazard in pregnancy. Agents - Vibration, which is likely to be enacted in law in 1996 or 1997, is seeking to impose extremely conservative upper limits for the daily vibration exposure of employees (even where not pregnant)

Although formal studies are few, the effects on pregnancy of prolonged handtransmitted vibration are likely to be similar to those for whole-body vibration.
Moreover, the EC Directive on Physical
MO should restrict pregnant physiotherapists from all duties involving short-wave therapeutic equipment.

Pregnant servicewomen complaining of soft tissue or skeletal injuries should not be referred by $\mathrm{MO}$ for any treatment involving short-wave therapeutic equipment.

MO should restrict pregnant servicewomen from all duties with Clansman HF or VHF sets, or any other high-frequency radio sets.

Where advice is sought from a pregnant VDU user, MO should offer reassurance that there is no substantiated risk.

If the individual remains unconvinced or anxious the MO should agree to restrict her work with VDUs.

As a sensible precaution, MO should restrict pregnant servicewomen from any travel in tracked vehicles.

The same exclusion should apply to any travel (unless of only a few minutes' duration) in rotary wing aircraft, ie helicopters.

As a sensible precaution, MO should restrict pregnant servicewomen from all exposure to gunfire noise. Therefore:

- Pregnant servicewomen should not be armed.

They should not take part in any range duties, nor any military exercise where they are likely to be exposed at close range to small arms noise heavy weapons noise, or pyrotechnics noise.

As a sensible precaution, MO should impose the following restrictions on the employability of pregnant servicewomen.

- No off-road travel in military vehicles.

- No usage of fork lift trucks.

- Only limited travel (no more than a few minutes' duration) in rotary wing aircraft, ie helicopters.

Based on a detailed work history, MO should restrict prolonged usage in pregnancy of:

- Pneumatic or electric power tools (eg drilling machines, power saws, grinders, chipping hammers).

- Vibrating workpieces (eg mobile generators, compressors, pumps).

Some studies (26) have shown heavy lifting in pregnancy to constitute a hazard to the fetus.
MO should restrict all duties involving heavy lifting (eg movement of stores, erection of tentage, casualty handling).

There is likely to be a hazard in many RA and RE trades, also RAMC, RADC, QARANC. 
Table 1 - continued

\section{Workplace Hazards to Pregnancy Servicewomen - Physical Agents}

\begin{tabular}{lll}
\hline \multicolumn{1}{c}{ Agent } & Human Reproductive Hazard \\
1.9 & LONG/ & ??Preterm labour. \\
IRREGULAR & ??Low birth weight. \\
HOURS OF & WORK
\end{tabular}

1.10 NIGHT WORK ??Adverse outcome of pregnancy.

\section{Scientific Evidence}

Some studies $(17,27)$ have suggested that long/irregular hours of work are a hazard in pregnancy.

However, there are also conflicting studies of no effect with this parameter (14).
Recommendation for Medical Officer (MO)

MO should consider restricting work where there is a likelihood of a pregnant servicewoman having to undertake particularly long and irregular hours of work.
Animal studies have shown that the fetu is adversely affected by inversion of the normal light/dark cycle of the mother (28).

There are no known human studies demonstrating a causal relationship between night work and damage to the fetus.

\subsection{PHYSICAL EXERCISE \\ ??Adverse outcome of pregnancy, if excessive.}

In fact, maternal exercise is welltolerated by the fetus at least up to $70 \%$ of maximal exercise.

The exercise should be in regular short bursts rather than arduous one-off efforts A maximum maternal heart rate of 140 beats/min is recommended (29). Exercise should be avoided only if there are any adverse obstetric history or risk factors, or a previous history of inactivity (29).

In fact the fetus is well-protected within the pelvis, and later in pregnancy by the layers of the abdominal wall and uterus, together with the amniotic fluid.

However, largely for medicolegal reasons, most sporting bodies bar pregnant women from participating beyond the second trimester (29).
As a sensible precaution, MO should restrict all night duties where the pregnant servicewoman complains of excessive fatigue resulting from night work.
Animal studies and retrospective data in women have shown maternal hyperthermia to be a risk factor. The prolonged fever $\left(>39^{\circ} \mathrm{C}\right.$ for 3 days $)$ cited in these reports, however, does not equate with the mild temperature changes experienced during most occupational activities (29).
MO should not restrict normal PT or adventurous training in a pregnant servicewoman, unless there are clear contraindications to physical exercise.

These contraindications include: acute infectious disease, multiple pregnancy, incompetent cervix, intrauterine growth retardation, hypertension, uterine bleeding, ruptured membranes.

Pregnant service women should not be permitted to undertake the Army's Basic Fitness Test or Combat Fitness Test.

MO should restrict all sports in all pregnant servicewomen after the first trimester.

Military parachuting must not be undertaken at any stage of pregnancy.

MO should advise pregnant servicewomen who work in equine divisions (eg RAVC and RMP personnel) to avoid all contact with horses on account of possible trauma. If this is impossible, the MO should consider imposing a formal restriction.

MO should advise pregnant servicewomen to exercise during the cool part of the day, and to ensure adequate hydraton at all times.

Pregnant servicewomen must not undertake NBC training, other than in NBC Dress Category Zero or NBC Dress Category 1.

\subsection{EXTREMES ?Adverse outcome of pregnancy OF COLD}

Some studies have shown cold to be a hazard in pregnancy.

However, there are also conflicting studies of no effect with this parameter (14).
MO should advise pregnant servicewomen of the theoretical risk. They should not undertake any adventurous training which might entail prolonged exposure to extreme cold

During exceptionally cold weather (eg in Germany, Norway) pregnant servicewomen should be excused guard duty.

MO must assess the risk realistically.

is anecdotal evidence in the obstetrical literature of low voltage (110-220 volts) electric shock to a pregnant woman having the potential for harm to the fetus, including fetal death $(30)$.
In most military employments, and with most electrical equipments, there is likely to be no danger at all to the pregnant servicewoman.

Where there is a known danger of electrical hazard from old or unreliable military equipment (as eg from some armoured fighting vehicle power packs) the MO should restrict pregnant servicewomen from all contact with such equipment. 
guidelines and re-issued them in a modified form, for the use of employing officers in all Arms and Services of the British Army. This ensured that employers and their medical advisers would in the future be of one of mind regarding the necessary restrictions to be placed on the employability of any servicewomen who happened to be pregnant.

\section{Discussion}

The literature search strategy adopted for this study, and the overview and recommendations which followed from it, are open to some criticism on methodological grounds.

The exclusive concentration on published evidence of reproductive hazards makes it likely that some of the conclusions reached will have been contaminated by publication bias. As is now well recognised $(1,2,3)$, small positive studies are more likely to be published than negative ones, potentially distorting the findings of any overview which does not at the same time endeavour to include unpublished evidence.

A further source of potential bias arises from the fact that because of limited time and resources the only database searched was Medline, and furthermore the search was restricted to relevant studies that were published in English only. It is possible that some important studies were missed that appeared in databases other that Medline, and in languages other than English. For this particular research task, however, it was felt that the latter risk was small since from an early stage of the search process it was clear that the vast majority of studies relating to reproductive health and safety had indeed been published in English (having originated either in Britain/North America or in Scandinavia).

A further criticism of the search methodology follows from the fact that the sensitivity of Medline can be poor, and in some electronic searches has been shown to be as low as $51 \%$ against a hand-searched "gold standard" (4). Even with the most diligent searching of Medline, therefore, studies will be missed which are in fact indexed on the database, but are not located by the searcher. The reason for this in most cases will be that the authors did not clearly describe the aims and methods of their research, or else that the coding procedures of the US National Library of Medicine (which "owns" Medline) were not properly applied (5). In the case of the present study the impact of this potential limitation was minimised through considerable reliance on the searching skills and advice of a trained medical librarian.

Lastly, the "on average" reviewing strategy adopted for the study has the fault of lacking in scientific rigor. In such "traditional" reviews of the literature, too much depends on the individual perspective and private judgement of the reviewer, and hence true objectivity can be lost (6). An on-the-average review, therefore, would not occupy a high place in the "hierarchy of validity" originally proposed by Oxman and Guyatt (7) Notwithstanding this, the on-the-average summary is accepted by Light and Pillemer (8) and other respected academic authorities as being a legitimate research tool for obtaining answers to policy questions where there is need for swift and decisive action.

Table 2

\section{Workplace Hazards to Pregnancy Servicewomen - Biological Agents}

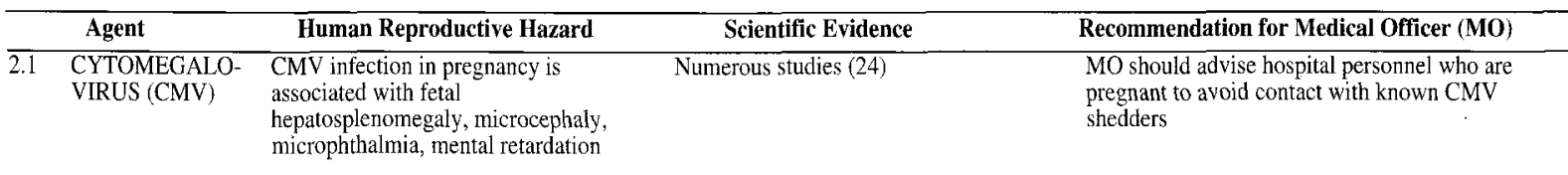

2.2 TOXOPLASMA GONDII
Toxoplasma gondii is an intracellular coccidian protozoan of cats, and the cause of toxoplasmosis. This is a common infection which is frequently asymptomatic or else presents as an infectious disease resembling infectious mononucleosis

A primary infection during early pregnancy, however, may lead to fetal infection with death of the fetus or choreoretinitis, brain damage with intracerebral calcification, hydrocephaly, microcephaly, fever, jaundice, rash, hepatosplenomegaly and convulsions evident at birth or shortly thereafter.

Maternal infection later in pregnancy results in mild or subclinical fetal disease with delayed manifestations, especially recurrent or chronic chorioretinitis.
Numerous studies (31)

MOs should be aware of the risk to:

Pregnant RAVC personnel who work in veterinary hospitals which operate on cats.

- Pregnant RAVC or RMP personnel who work in equine divisions (where barn cats are an essential part of the establishment).

They should advise such personnel accordingly, and if necessary impose a formal restriction on any contact with cats. 
Table 3

Workplace Hazards to Pregnancy Servicewomen - Chemical Agents

\begin{tabular}{|c|c|c|c|}
\hline Agent & Human Reproductive Hazard & Scientific Evidence & Recommendation for Medical Officer (MO) \\
\hline $3.1 \quad$ LEAD & $\begin{array}{l}\text { Reduced fertility, spontaneous } \\
\text { abortion, prematurity, stillbirth, } \\
\text { neonatal death, congenital }\end{array}$ & Numerous studies $(32,33)$ & $\begin{array}{l}\text { MO should restrict pregnant servicewomen from } \\
\text { all duties within indoor firing ranges. }\end{array}$ \\
\hline
\end{tabular}

malformations, abnormal central

nervous systems development,

behavioural abnormalities

3.2 BENZENE Vaginal bleeding, haemorrhagic complications of pregnancy, spontaneous abortion.
Numerous studies (34)

It should be noted that petrol by law may contain up to $5 \%$ benzene.

Diesel fuel, on the other hand may contain a variable amount of benzene. Currently, the levels are not regulated by law.
MO should restrict pregnant servicewomen from any direct contact with benzene or with benzene vapour, even when wearing protective equipment.

Pregnant women should not be permitted to refuel military vehicles at any time.

This applies also to military drivers, who must not refuel their own vehicle if pregnant.

\subsection{CARBON Neurological damage to fetus, MONOXIDE fetal growth retardation.} all duties in vehicle parks, other than brief visits.
MO should restrict pregnant servicewomen from
Carbon monoxide readily crosses the placenta and is likely to cause reduced fetal haemoglobin concentration. The potential for this hazard has been demonstrated in numerous studies (34).

It should be noted that vehicle exhausts contain carbon monoxide as well as oxides of nitrogen (which are also believed to have an adverse effect on pregnancy).

\subsection{ANAESTHETIC \\ Spontaneous abortion (one-and-a- \\ Numerous retrospective studies (35)} GASES half to threefold increase).

?Fetal growth retardation, congenital malformation, low birth weight, stillbirth.
MO should restrict RAMC, RADC, QARANC and RAVC servicewomen who are pregnant from any exposure to anaesthetic gases.

This applies to surgeons, anaesthetists, operating theatre nurses, operating theatre technicians, etc.
Numerous studies $(17,36)$

\section{Pregnant doctors and nurses administering antimitotic agents (even when doing so with extreme care) have shown a significant increase in fetal loss and/or congenital malformations. \\ 3.5 ANTIMITOTIC DRUGS}

\begin{abstract}
Mefloquine in teratogenic when administered to rats and mice in early gestation. Its prophylactic use during human pregnancy should therefore be avoided as a matter of good clinical practice (37).

Pregnancy should also be avoided for 3 months after completing a course of mefloquine, on account of its long half-life (37).
\end{abstract}

MO should restrict pregnant RAMC and QARANC servicewomen (including doctors, nurses, pharmacists and pharmacy technicians) from handling antimitotic drugs in any form.

\subsection{ANTIMALARIAL ?Congenital malformations CHEMOPRO- - MEFLOQUINE}

MO should not prescribe mefloquine to any servicewoman travelling to a malarious area, unless there is no risk at all of pregnancy (eg following hysterectomy, bilateral oophorectomy or tubal ligation).
Various studies (38)

?Spontaneous abortion.

??Congenital malformations

$\begin{array}{lll}3.7 & \text { PESTICIDES } & \text { ?Spontaneous abortion. } \\ & \text { ??Congenital malformations } & \end{array}$

3.8 CS GAS
No known studies
Although the majority of Service-approved pesticides are likely to pose no threat at all in pregnancy, $\mathrm{MO}$ should nevertheless restrict pregnant servicewomen from all duties involving the use of pesticides.

As a sensible precaution, $\mathrm{MO}$ should restrict pregnant servicewomen from any exposure to $\mathrm{CS}$ gas, eg during NBC training.

See also the restriction at Table 1.13. 


\section{Outcome}

Initial user response to the guidelines has been favourable. The guidelines are felt to have filled a serious policy gap in the delivery of responsible medical care to those servicewomen who exercise their statutory right to become pregnant. As at 1 April $1994,7 \%$ of all UK Regular Forces were female (9). In the case of the Army, 187 female personnel out of a total female strength of 7,052 took maternity leave during 1993/94. This equates to a general fertility rate within the British Army of approximately 26.5 live births per annum per 1,000 servicewomen of childbearing age. The rate is likely to increase over time, as pregnancy amongst servicewomen becomes increasingly acceptable, and maternity rights more extensive.

The guidelines have proved to be especially timely in the light of the government's decision during 1994 to implement the health and safety provisions of the EC Pregnant Workers Directive (10). The implementation was accomplished through the Management of Health and Safety at Work (Amendment) Regulations (11), which came into effect on 1 December 1994. Under the

regulations employers are required to assess any risks within their undertaking to the health of new and expectant mothers in their employment, and to take all "reasonably practical" steps to control those risks. Military employers would normally rely on their unit medical officers to provide them with detailed, scientific advice on how to carry out all stages of this risk assessment.

For some of the hazards identified, AMD5's guidelines have proved to be more proscriptive than the national guidelines (12) which the Health and Safety Executive issued in December 1994, to complement the new regulations. This can be justified on the grounds that MOD has consistently aspired to a standard of occupational health and safety which is at least as high as the best civilian industrial practice, and where possible higher. Moreover, defensive medicine is now accepted as a normal component of prudent medical practice (13) and it could be argued that where Service pregnancies are concerned it is appropriate that the attending medical staff should engage in it.

It is thought that AMD5's study is the first

Table 4

Workplace Hazards to Pregnancy Servicewomen - Working Conditions

\begin{tabular}{|c|c|c|c|c|}
\hline & Working Condition & Human Reproductive Hazard & Scientific Evidence & Recommendation for Medical Officer (MO) \\
\hline 4.1 & DIVING & ?Adverse outcome of pregnancy & $\begin{array}{l}\text { Hyperbaric oxygen (ie the standard } \\
\text { treatment for decompression illness) } \\
\text { is known to damage the fetus (39). }\end{array}$ & $\begin{array}{l}\text { Military diving must not be undertaken at any } \\
\text { stage of pregnancy. }\end{array}$ \\
\hline
\end{tabular}

4.2 FLYING - ?Low birthweight AIRCREW
??Congenital abnormalities
The partial pressure of oxygen within aircraft cabins is normally low, approximating to an altitude of $1520-2440 \mathrm{~m}$ ( 40 ), with oxygen concentrations ranging from $15.2 \%$ to $17.6 \%(41)$.

In the case of a pregnant member of the aircrew, this would result in a slightly reduced haemoglobin oxygen saturation, in both mother and fetus.

Any extended exposure to a low partial pressure of oxygen is thought to constitute a threat to the fetus (42).

In addition, flying duties involve risks to the pregnant servicewoman from prolonged noise exposure, and from whole-body vibration.

\subsection{FLYING - PASSENGERS}

There is probably no risk to infrequent passengers from the low partial pressure of oxygen within aircraft.

Should pregnant passengers elect to fly in advanced pregancy, however, there is a risk of preterm labour due to the changes in ambient atmospheric pressure (43).
MO should restrict pregnant aircrew from all flying duties.

Any pregnant servicewoman who is between her 32nd and 36th week of pregnancy must be examined by a medical officer before she can be considered fit to fly in an RAF or MOD-chartered aircraft.

Between the 35th and 36th week of pregnancy it is prudent to restrict air travel to short journeys only (43).

After the 36th week of pregnancy air travel in an RAF or MOD-chartered aircraft will only be authorised as an aeromedical patient.

KEY: ? = Evidence for reproductive hazard is inconclusive.

$? ?=$ Evidence for reproductive hazard is scanty, or non-existent 
Table 5

Workplace Hazards to Breastfeeding Servicewomen - Chemical Agents

\begin{tabular}{|c|c|c|c|c|}
\hline & Agent & Human Reproductive Hazard & Scientific Evidence & Recommendation for Medical Officer (MO) \\
\hline 5.1 & LEAD & $\begin{array}{l}\text { Lead can enter maternal milk and } \\
\text { may cause abnormal central } \\
\text { nervous system development in the } \\
\text { lactating infant. }\end{array}$ & Limited studies (33) & $\begin{array}{l}\text { MO should restrict servicewomen who are } \\
\text { breastfeeding from all duties within indoor firing } \\
\text { ranges. }\end{array}$ \\
\hline \multirow[t]{2}{*}{$\overline{5.2}$} & PESTICIDES & $\begin{array}{l}\text { Certain pesticides (eg chlordecone } \\
\text { [Kepone]) appear as concentrates in } \\
\text { maternal milk. }\end{array}$ & Limited studies (34) & $\begin{array}{l}\text { MO should restrict servicewomen who are } \\
\text { breastfeeding from all duties involving the use of } \\
\text { pesticides. This applies to:- }\end{array}$ \\
\hline & & $\begin{array}{l}\text { The health risks to the lactating } \\
\text { infant are variable. }\end{array}$ & & $\begin{array}{l}\text { Female Environmental Health Technicians. } \\
\text { Female unit pest control personnel. }\end{array}$ \\
\hline
\end{tabular}

comprehensive appraisal to have been conducted by any Defence organisation of reproductive hazards in the military environment. It is acknowledged that in the course of time new hazards will emerge and existing hazards will assume greater or less prominence. The guidelines will need to be revised periodically.

Pregnancy in the workplace is a highly emotive issue which carries severe economic penalties if the medical attendant or the employer can be shown, through civil litigation, to have been negligent. It is hoped that AMD5's medical guidelines on employability during pregnancy and lactation will help reduce the incidence of such penalties, to the mutual benefit of all parties.

\section{Acknowledgments}

I should like to thank the following for their advice and encouragement in carrying out this study: Maj Gen (Retd) JT Coull Late RAMC, Col FT Adams Late RAMC, Lt Col TP Finnegan RAMC, Lt Col SA StJ Miller RAMC, Capt SG Nash RAMC(V), Prof J Arendt, Prof JM Harrington CBE, Dr IM Calder, Dr EG Jessop and Mr M Forrest. I am particularly grateful to Ms Marie Porter of Royal Army Medical College Library for her help with the literature searches.

\section{REFERENCES}

1. EGGER M, SMITH GD. Misleading meta-analysis. $\mathrm{Br}$ Med J 1995; 310: 752-4.

2. Easterbrook PJ, Berlin JA, Gopalan R, MatThews DW. Publication bias in clinical research. Lancet 1991; 337: 867-72.

3. Dickersin K, Min YI, Meinert CL. Factors influencing publication of research results: follow-up of applications submitted to two institutional review boards. JAMA 1992; 263: 374-78.

4. Dickersin K, Scherer R, Lefebvre C. Identifying relevant studies for systematic reviews. $B r$ Med $J$ 1994; 309: 1286-91.

5. Chalmers I, Dickersin K, Chalmers TC. Getting to grips with Archie Cochrane's agenda. Br Med J 1992; 305: 786-8.

6. Chalmers I. Improving the quality and dissemination of reviews of clinical research. In: LOCK SP, ed. The
Future of Medical Journals. London: BMJ Publishing Group, 1992; 127-46.

7. OXMAN AD, GuYatT GH. Guidelines for reading literature reviews. Can Med Assoc $J$ 1988; 138: 697703.

8. Light RJ, Pillemer DB. Summing Up. The Science of Reviewing Research. London: Harvard University Press, 1984.

9. Ministry of Defence. UK Defence Statistics. London: HMSO, 1994.

10. Council Directive 92/85/EEC of 19 October 1992. In Consultative Document. Proposals for the Manage ment of Health and Safety at Work (Amendmenis Regulations 199-. London: Health and Safety Comb mission, 1994: 14-21.

11. SI No 2865. The Management of Health and Safety at Work (Amendment) Regulations. London: HMSG 1994.

12. Health and Safety Executive. New and expectan mothers at work. A guide for employers. Sheffield: HSE Books, 1994.

13. Summerton N. Positive and negative factors in defensive medicine. Br Med J 1995; 310: $27-9$.

14. Barlow SM, Dayan AD, Powell CJ. Reproductive hazards at work. In: RAFFLE PAB, ADAMS PH, BAzTER PJ, LeE WR, eds. Hunter's Diseases of Occupations. London: Edward Arnold, 1994; 723-42.

15. Baltzar B, Ericson E, Kallén B. Pregnancy outcome among women working in Swedish hospitals. $N$ Engl J Med 1979; 300: 627-8.

16. KALLÉN B. Delivery outcome among physiotherapists in Sweden: is non-ionising radiation a fetal hazard? Arch Environ Health 1982; 37: 81-4.

17. MCDONALD AD. Work and pregnancy. Editorial. $\mathrm{Br} J$ Ind Med 1988; 45: 577-80.

18. BERGQVisT U. Visual display terminals and health. Scand J Work Environ Health 1984; 10 suppl 2: 1-87.

19. Proceedings of the International Scientific Conference on Work with Visual Display Units, Stockholm 1986. Stockholm: Elsevier, 1987.

20. World Health Organisation. Visual Display Terminals and Workers' Health. Geneva: WHO, 1987.

21. BlaCKWEll R, Chang A. Video display terminals and pregnancy: a review. Br J Obstet Gynaecol 1988; 95: 446-53. 
22. HUNT VR. The physical environment. Work and the Health of Women. Boca Raton: CRC Press, 1979; 6195.

23. NuRminen T, KuRPPA K. Occupational noise exposure and course of pregnancy. Scan $J$ Work Environ Health 1989; 15: 117-24.

24. RUDOLPH L, FoREST CS. Female reproductive toxicology. In LADou J, ed. Occupational Medicine. London: Prentice-Hall International, 1990: 275-296.

25. Goulet L, Thériault G. Association between spontaneous abortion and ergonomic factors. A literature review of the epidemiological evidence. Scand $J$ Work Environ Health 1987; 13: 399-403.

26. Ahlborg G, Bodin L, Hogstedt C. Heavy lifting during pregnancy - a hazard to the fetus? Int J Epidemiol 1990; 19: 90-7.

27. Mamelle N, Laumon B. Occupational fatigue and preterm birth. In: Chamberiain G, ed. Pregnancy Women at Work. London: Royal Society of Medicine and Macmillan Press, 1984: 105-15.

28. BeVESON S, Forsyth IA, ARENDT J. Retardation of pubertal development by prenatal long days in goat kids born in autumn. J Reprod Fertil 1992; 95: 62937.

29. Carbon R. Female athletes. $\mathrm{Br}$ Med $J$ 1994; 309: 254-8.

30. Moore AB. Electrical contact and pregnancy. J Occup Med 1991; 31: No 7, 827-8.

31. BenEnson AS, ed. Control of Communicable Diseases in Man. Washington: American Public Health Association. 1990.

32. ANGLE CR, MCINTIRE MS. Lead poisoning during pregnancy. Am J Dis Child 1964; 108: 436-9.
33. RoM WN. Effects of lead on the female and reproduc tion: a review. Mt Sinai J Med 1976; 43: 542-52.

34. Barlow SM, Sullivan FM. Reproductive Hazards of Industrial Chemicals. London: Academic Press, 1982.

35. Tannebaum TN, Goldberg RJ. Exposure to anaesthetic gases and reproductive outcome. J Occup Med 1985; 27: 659-68.

36. STUCKER I. Risk of spontaneous abortion among nurses handling antineoplastic drugs. Scand J Work Environ Health 1990; 16: 102-7.

37. Association of the British Pharmaceutical Industry Data Sheet Compendium. London: Datapharm Publications, 1994.

38. FLETCHER AC. Reproductive Hazards of Work. Manchester: Equal Opportunities Commission, 1985.

39. US Navy. Diving Manual. NAVSEA 0994-LP001 9010. Washington DC: Navy Department, 1985.

40. Commission on Emergency Medical Services, American Medical Association. Medical aspects of transportation aboard commercial aircraft. JAMA 1986; 247: 1007-11.

41. Cottrell JJ. Altitude exposures during aircraft flight Chest 1988; 92: 81.

42. McMillan GHG, ed. Health and Safety at Work. Th

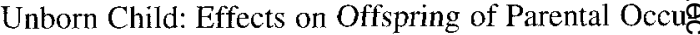
pational Exposure. Proceedings of a Society od Occupational Medicine Research Panel Symposiun Held at the Royal Army Medical College Millbank om 20 February 1980. London: Society of Occupationas Medicine, 1981: 62-3.

43. Walker E, Williams G, Raeside F. ABC of Health Travel. London: BMJ Publishing Group, 1993. 